\title{
Shaping Arctic's Tomorrow through Indigenous Knowledge Engagement and Knowledge Co-Production
}

\author{
Tatiana Degai ${ }^{1,2,3, *(\mathbb{D})}$, Andrey N. Petrov ${ }^{2,4}$ (D), Renuka Badhe ${ }^{5}$, Parnuna P. Egede Dahl ${ }^{6,7,8}$, Nina Döring 9 , \\ Stephan Dudeck $\left.{ }^{10}{ }^{(}\right)$, Thora M. Herrmann ${ }^{11,12}$, Andrei Golovnev ${ }^{13}$, Liza Mack ${ }^{14}$, Elle Merete Omma ${ }^{15}$, \\ Gunn-Britt Retter ${ }^{15}$, Gertrude Saxinger ${ }^{16}$, Annette J. M. Scheepstra ${ }^{17}$, Chief Vyachelav Shadrin ${ }^{18,19}$, \\ Norma Shorty ${ }^{20}$ and Colleen Strawhacker ${ }^{21}$
}

check for updates

Citation: Degai, T.; Petrov, A.N.; Badhe, R.; Egede Dahl, P.P.; Döring, N.; Dudeck, S.; Hermann, T.M.; Golovnev, A.; Mack, L.; Omma, E.M.; et al. Shaping Arctic's Tomorrow through Indigenous Knowledge Engagement and Knowledge Co-Production. Sustainability 2022, 14 , 1331. https://doi.org/10.3390/ su14031331

Academic Editors: Gail Fondahl, Grete K. Hovelsrud, Tero Mustonen and Stephanie Pfirman

Received: 21 September 2021 Accepted: 7 December 2021 Published: 25 January 2022

Publisher's Note: MDPI stays neutral with regard to jurisdictional claims in published maps and institutional affiliations.

Copyright: (c) 2022 by the authors. Licensee MDPI, Basel, Switzerland. This article is an open access article distributed under the terms and conditions of the Creative Commons Attribution (CC BY) license (https:// creativecommons.org/licenses/by/ $4.0 /)$.
1 Department of Anthropology, University of Victoria, Victoria, BC V8P 5C2, Canada

2 Department of Geography, ARCTICenter, University of Northern Iowa, Cedar Falls, IA 50614, USA; andrey.petrov@uni.edu

3 Council of Itelmens of Kamchatka “Tkhsanom”, 683000 Petropavlovsk-Kamchatski, Russia

4 International Arctic Social Sciences Association (IASSA), Nord University, Universitetsalleen 11, 8049 Bodø, Norway

5 Gaffelstraat, 2584SJ Den Haag, The Netherlands; renuka@cantab.net

6 Department of Arctic Social Science \& Economics, Institute of Social Science, Economics \& Journalism, University of Greenland, 3905 Nuussuaq, Greenland; parnuna@plan.aau.dk

7 Department of Planning, Technical Faculty of IT and Design, Danish Centre for Environmental Assessment, Aalborg University, 9000 Aalborg, Denmark

8 Inuit Circumpolar Council-Greenland, 3900 Nuuk, Greenland

9 Institute for Advanced Sustainability Studies, 14467 Potsdam, Germany; nina.doering@iass-potsdam.de

10 Centre for Arctic Social Studies, European University at Saint Petersburg, 191187 Saint Petersburg, Russia; sdudeck@ulapland.fi

11 Helmholtz Centre for Environmental Research-UFZ, 04318 Leipzig, Germany; thora.herrmann@idiv.de

12 German Centre for Integrative Biodiversity Research (iDiv) Halle-Jena-Leipzig, 04103 Leipzig, Germany

13 Peter the Great Museum of Anthropology and Ethnography (the Kunstkamera) of the Russian Academy of Sciences, 199034 Saint Petersburg, Russia; andrei_golovnev@bk.ru

14 Aleut International Association, Anchorage, AK 99503, USA; liza.mack@aleut-international.org

15 Saami Council, 9735 Karasjok, Norway; elle.merete@saamicouncil.net (E.M.O.); gbr@saamicouncil.net (G.-B.R.)

16 Department of Political Science, Uni Vienna (AT), Austrian Polar Research Institute APRI, 1090 Wien, Austria; gertrude.saxinger@univie.ac.at

17 Arctic Centre, University of Groningen, 9700 AB Groningen, The Netherlands; a.j.m.scheepstra@rug.nl

18 Yukaghir Council of Elders, 677007 Yakutsk, Russia; odul.shadrin@gmail.com

19 The Institute for Humanities Research and Indigenous Studies of the North, Russian Academy of Sciences, 677007 Yakutsk, Russia

20 Arctic Athabaskan Council, Whitehorse, YT Y1A 5X9, Canada; 1012secondstreet@gmail.com

21 Office of Polar Programs, National Science Foundation, 2415 Eisenhower Ave, Alexandria, VA 22314, USA; colstraw@nsf.gov

* Correspondence: tatianadegai@uvic.ca

Abstract: This perspective presents a statement of the 10th International Congress of Arctic Social Sciences Indigenous Knowledge and knowledge co-production panel and discussion group, 20 July 2021. The statement is designed to serve as a characterization of the state-of-the-art and guidance for further advancement of Indigenous Knowledge and knowledge co-production in the Arctic. It identifies existing challenges and provides specific recommendations for researchers, Indigenous communities, and funding agencies on meaningful recognition and engagement of Indigenous Knowledge systems.

Keywords: Indigenous Knowledge; co-production; Arctic; Indigenous Peoples 


\section{Introduction}

Indigenous Knowledge and knowledge co-production are central for both research and policymaking in the Arctic, now and in the future. The International Arctic Social Sciences Association (IASSA), a professional society that brings together social scientists, humanities and Indigenous scholars, has long elevated the Indigenous Knowledge systems in its agenda. In 2017 IASSA adopted a statement on the Indigenous Knowledge and in 2021 it revised its Principles and Guidelines for Conducting Ethical Research in the Arctic to ensure productive and equitable engagement of Indigenous Knowledge, unconditional adherence to principles of Indigenous data and knowledge sovereignty and commitment to decolonizing research through knowledge co-production. IASSA members continued this work, and these efforts culminated in developing a new vision for Indigenous Knowledge engagement and co-production in the Arctic that is discussed below.

\section{Indigenous Knowledge Is Key to Understanding Natural and Social Systems in the Arctic}

On 20 June 2021, the International Congress of Arctic Social Sciences (ICASS X) hosted a plenary and other sessions devoted to the Indigenous Knowledge and research in the Arctic. The panelists and presenters have developed the following statement.

The Indigenous Peoples are the original Arctic researchers who hold unique knowledge, grounded in multigenerational experiences, of land and environment. This knowledge is time tested and implies deep understanding of the Arctic environment, socioeconomic systems, and human-environment relations. Indigenous Knowledge provides a foundation for individual and collective well-being of past, present, and future generations of Arctic Indigenous Peoples. Indigenous Knowledge systems have their own ontologies, epistemologies, and methodologies, and possess internal validation principles and processes based on reciprocity and respect. Indigenous Knowledge is key to accurate interpretation of dynamics in the natural and social systems in the Arctic. Science and policy that are not inclusive of the Indigenous Knowledge cannot be considered adequate to address the Arctic Peoples' needs. A major advancement in Arctic science will be achieved through Indigenization of Arctic research.

While working with Indigenous communities, one has to be mindful of the systemic trauma they have experienced in their history, and allow time, and channel resources so that these communities can heal and reconcile with their land, histories and languages that were disrupted due to colonization.

\section{Co-Production Must Become a Priority}

In order to ensure the vitality of Indigenous Knowledge systems and to improve the quality and relevance of Arctic research, collaborative efforts across disciplines under the guidance of the Indigenous Knowledge holders must become a priority, and knowledge co-production must be seen as central for Arctic research. Co-production must be based on ethical, equitable, meaningful and mutually beneficial engagement of knowledge systems that is embedded in Indigenous rights, recognition of Indigenous Knowledge sovereignty and ownership. Co-production must be recognized, promoted and supported by funding agencies, academic institutions, and researchers regardless of their discipline, area of research and affiliation.

Co-production should imply co-identification of research needs, co-creation of research ideas, co-design of research questions, co-definition of research objectives, co-development of research programs, co-authorship of research results, co-implementation of research projects and co-evaluation of research outcomes. Co-production must ensure that Indigenous and non-Indigenous research partners share a common vision of what these, and other terms, mean in the research process. In addition to being based on co-production, Arctic research must also make room for Indigenous Peoples' knowledge systems to stand on their own without being validated by research partnerships with non-Indigenous scholars.

Finally, co-production should generate practical results important for Indigenous communities. It is important to acknowledge that these processes take time. 


\section{Practical Steps to Be Taken Now}

To take steps towards achieving the above goals, we recommend the following: Recognize and respect Indigenous Knowledge in understanding natural and social systems in the Arctic including the importance of data sovereignty, intellectual property and ownership by Indigenous rights holders.

- Support the Indigenous Peoples to identify, define, research and act upon their own research priorities and methodologies, for example by providing financial, organizational and institutional capacities.

- Enable and encourage development of equitable relationship and understanding between the Indigenous Peoples and researchers necessary to co-create meaningful, relevant research guided by Indigenous Knowledge and societal values.

- Focus on reciprocal, mutually enriching capacity building between researchers and Indigenous communities:

- $\quad$ this includes building capacity among researchers to recognize Indigenous rights and fully engage Indigenous Knowledge in Arctic research.

- engaging Indigenous youth and elders to have an active role in knowledge production.

- Encourage research institutions and funding agencies to support and enable meaningful collaboration at all stages of research projects in the social and natural sciences and humanities to meet the expectations of knowledge co-production.

- Urge funding agencies to provide research-planning (seed) funding, flexible funding, and long-term funding options to researchers and Indigenous organizations to establish, build, and maintain relationships with Indigenous communities and to lay the foundation for knowledge co-production prior to actual research.

- Recommend that research institutions and funding agencies engage and support Indigenous Peoples to evaluate the research before, during and after the research to ensure that the research is progressing in a way that meets their needs.

- Prioritize collaboration, co-creation, Indigenous-led projects and capacity building research initiatives in funding calls and in the project selection process.

Finally, recognizing sustained commitment and extensive work that the International Arctic Social Sciences Association (IASSA) has done to advance the role of the Indigenous Knowledge in Arctic research and promote knowledge co-production, it is important to continue by focusing on:

- facilitating the equitable and ethical application of Indigenous Knowledge and engagement of Arctic Indigenous communities by developing guidance to the international research community in all aspects of Arctic science and research.

- working on creation of intellectual space for Indigenous Knowledge holders at international fora.

- further engaging Indigenous Knowledge holders in IASSA.

- developing internal IASSA strategies, structures and resources to establish a support system of Indigenous Knowledge holders within the IASSA, e.g., an Indigenous Knowledge Working Group.

\section{Conclusions}

Diverse Indigenous Knowledge systems in the Arctic are critical for ensuring the wellbeing of Arctic communities and ecosystems. They are central for accurate interpretation of the natural and social dynamics in the Arctic. Equitable engagement and co-production are the primary mechanisms for decolonizing and Indigenizing Arctic research and policymaking that will secure a sustainable Arctic tomorrow. Attaining these goals will take a collective effort and individual commitment. The authors and IASSA are determined to continue this work. Ultimately, we call on individual researchers to ask themselves: what can I do to make this happen? 
Author Contributions: Conceptualization, all; formal analysis, all; writing-original draft preparation, T.D. and A.N.P.; writing-review and editing, all; project administration, T.D.; funding acquisition, A.N.P. All authors have read and agreed to the published version of the manuscript.

Funding: This research was funded by the US National Science Foundation, grant number 2001989.

Institutional Review Board Statement: Not applicable.

Informed Consent Statement: Not applicable.

Data Availability Statement: Not applicable.

Acknowledgments: This paper was informed by the research conducted on traditional lands that continue to be stewarded by the Indigenous Peoples of the Arctic. The authors are thankful to participants of the ICASS X plenary and other sessions devoted to the Indigenous Knowledge in the Arctic and anonymous reviewers for their valuable comments and suggestions. We are also grateful to Sustainability Journal and Special Issue editors for waving the publication fee for this contribution thus demonstrating commitment to enhancing equity in access to publishing for diverse Arctic knowledge holders.

Conflicts of Interest: The authors declare no conflict of interest. 